\title{
Suppression of glucagon secretion is lower after oral glucose administration than during intravenous glucose administration in human subjects
}

\author{
J. J. Meier • C. F. Deacon • W. E. Schmidt • J. J. Holst • \\ M. A. Nauck
}

Received: 27 September 2006 / Accepted: 27 December 2006 / Published online: 16 February 2007

(C) Springer-Verlag 2007

\begin{abstract}
Aims/hypothesis The incretin effect describes the augmentation of postprandial insulin secretion by gut hormones. It is not known whether glucagon secretion is also influenced by an incretin effect. A glucagon suppression deficiency has been reported in some patients with type 2 diabetes, but it is unclear whether this abnormality is present prior to diabetes onset. We therefore addressed the questions: (1) Is glucagon secretion different after oral and during intravenous glucose administration? (2) If so, is this related to the secretion of incretin hormones? (3) Is glucagon secretion abnormal in first-degree relatives of patients with type 2 diabetes?

Materials and methods We examined 16 first-degree relatives of patients with type 2 diabetes and ten matched control subjects with an oral glucose load (75 g) and with an 'isoglycaemic' intravenous glucose infusion.

Results Glucagon levels were significantly suppressed by both oral and intravenous glucose $(p<0.0001)$, but glucagon suppression was more pronounced during intravenous
\end{abstract}

J. J. Meier $(\bowtie) \cdot$ W. E. Schmidt

Department of Medicine I, St. Josef-Hospital,

Ruhr-University Bochum,

Gudrunstr. 56,

44791 Bochum, Germany

e-mail: juris.meier@rub.de

C. F. Deacon · J. J. Holst

Department of Medical Physiology, The Panum Institute,

University of Copenhagen,

Copenhagen, Denmark

M. A. Nauck

Diabeteszentrum Bad Lauterberg,

Bad Lauterberg, Germany glucose administration $(76 \pm 2 \%)$ than after oral glucose administration $(48 \pm 4 \% ; p<0.001)$. The differences in the glucagon responses to oral and i.v. glucose were correlated with the increments in gastric inhibitory polypeptide (GIP) $(r=0.60, p=0.001)$ and glucagon-like peptide (GLP)-1 $(r=0.46, p<0.05)$. There were no differences in glucagon levels between first-degree relatives and control subjects. Conclusions/interpretation Despite the glucagonostatic actions of GLP-1, the suppression of glucagon secretion by glucose is diminished after oral glucose ingestion, possibly due to the glucagonotropic actions of GIP and GLP-2. Furthermore, in this group of first-degree relatives, abnormalities in glucagon secretion did not precede the development of other defects, such as impaired insulin secretion.

Keywords First-degree relatives · Gastric inhibitory polypeptide - GIP - GLP-1 - Glucagon-like peptide 1 . Glucagon secretion · Incretin effect · Type 2 diabetes

\section{Abbreviations \\ GIP gastric inhibitory polypeptide \\ GLP glucagon-like peptide}

\section{Introduction}

Postprandial glucose homeostasis is tightly controlled by the interplay of gastric motility, endocrine pancreatic secretion and modulation of hepatic glucose release $[1,2]$. It has long been recognised that oral nutrient ingestion elicits a greater stimulation of insulin secretion than the intravenous infusion of a similar amount of glucose [3-5]. This manifestation of the incretin effect has been attributed 
to the actions of the gastrointestinal hormones gastric inhibitory polypeptide (GIP) and glucagon-like peptide (GLP)-1 [6, 7]. Overall, the incretin effect accounts for around $50-70 \%$ of the postprandial rise in insulin levels, depending on the amount of glucose ingested [4, 8]. However, while GIP and GLP-1 act in concert to stimulate glucose-dependent insulin secretion [7], they display marked differences with regard to their effects on glucagon secretion. Thus GLP-1 strongly suppresses glucagon secretion $[9,10]$, while GIP under certain conditions even stimulates glucagon release $[11,12]$. Furthermore, the other proglucagon-derived peptide, GLP-2, which is co-secreted along with GLP-1, has been shown to possess glucagonotropic properties as well [13]. The physiological consequences arising from the diverging actions of GIP, GLP-1 and GLP-2 for the postprandial regulation of glucagon secretion are as yet unknown.

Unlike healthy volunteers, patients with type 2 diabetes show only small differences in insulin secretion between oral and intravenous glucose administration [14]. This reduction in the incretin effect has been linked to diminished efficacy of GIP as well as a deficit in GLP-1 secretion and action [15-20]. In some patients with type 2 diabetes a reduced suppression of glucagon levels after meal ingestion has also been reported [21-23]. It is not clear whether such alterations in glucagon suppression represent a primary defect or whether they develop as a consequence of other metabolic defects in type 2 diabetes. The former alternative has been supported by previous studies showing a deficient suppression of glucagon secretion and, consequently, a diminished reduction in hepatic glucose output in subjects with IGT [24, 25].

First-degree relatives of patients with type 2 diabetes are another cohort at high risk of developing type 2 diabetes later during their life, the average risk being about $50 \%$ [26]. In previous studies we have shown that despite an approximately $50 \%$ reduction of the insulinotropic effect of GIP in a group of first-degree relatives of Europid origin, the quantitative contribution of the incretin effect to overall insulin secretion in these individuals was normal [17, 27]. In the present studies we sought to elucidate the potential impact of an incretin effect on the suppression of glucagon secretion in these individuals.

Therefore, glucagon measurements from the same study were analysed to address the following questions: (1) Is there a difference in the suppression of glucagon levels between oral and intravenous glucose administration? (2) If so, can such differences be attributed to the secretion of incretin hormones? (3) Are there any differences in the suppression of glucagon secretion after oral and during intravenous glucose administration between first-degree relatives of patients with type 2 diabetes and control subjects?

\section{Subjects and methods}

Study protocol The study protocol was approved by the ethics committee of the medical faculty of the RuhrUniversity, Bochum, prior to the experiments. Written informed consent was obtained from all participants. Parts of these studies relating to the differences in insulin secretion between first-degree relatives of patients with type 2 diabetes and control subjects have been reported in a previous paper [27].

Subjects We studied 16 first-degree relatives of patients with type 2 diabetes and ten control subjects without a family history of type 2 diabetes. First-degree relatives were recruited from the initial group of 21 subjects studied previously with the intravenous infusion of GIP [17]. In the control group of the initial cohort four members agreed to participate in the present study and six additional subjects were recruited. Since our previous study revealed a bimodal pattern of insulin secretion in the first-degree relatives [17], a higher number of first-degree relatives than controls were studied. The groups were matched for age, sex and obesity. Detailed subject characteristics are presented in Table 1 . Control subjects with any first- or second-degree relatives with type 2 diabetes were excluded after collation of their family health history.

Blood was drawn from all participants in the fasting state for measurements of standard haematological and clinical chemistry parameters. Spot urine was sampled for the determination of albumin, protein and creatinine by standard methods. Subjects with anaemia (haemoglobin $<120 \mathrm{~g} / \mathrm{l}$ ), with elevation in liver enzyme (alanine aminotransferase, aspartate aminotransferase, alkaline phosphatase, $\gamma$-glutamyl transferase) activities to greater than double the respective normal value or with elevated creatinine concentrations $(>114 \mu \mathrm{mol} / 1[1.5 \mathrm{mg} / \mathrm{dl}])$ were excluded. Body height and weight were determined and waist and hip circumference were measured in order to calculate BMI and the waist-tohip ratio, respectively (Table 1).

Table 1 Characteristics of first-degree relatives of patients with type 2 diabetes and of control subjects participating in oral glucose and 'isoglycaemic' intravenous clamp tests

\begin{tabular}{lccc}
\hline Variable & $\begin{array}{l}\text { First-degree relatives } \\
\text { of type 2 diabetic patients }\end{array}$ & $\begin{array}{c}\text { Control } \\
\text { subjects }\end{array}$ & $p$ value $^{\text {a }}$ \\
\hline Sex (men/women) & $4 / 12$ & $6 / 4$ & 0.11 \\
Age (years) & $50 \pm 12$ & $45 \pm 13$ & 0.30 \\
BMI (kg/m $\left.{ }^{2}\right)$ & $26.1 \pm 3.8$ & $26.1 \pm 4.2$ & 0.98 \\
WHR & $0.83 \pm 0.09$ & $0.88 \pm 0.09$ & 0.19 \\
$\mathrm{HbA}_{1 \mathrm{c}}(\%)$ & $5.1 \pm 0.3$ & $5.4 \pm 0.6$ & 0.08 \\
\hline
\end{tabular}

Mean \pm SD

${ }^{\mathrm{a}} \mathrm{ANOVA} / \chi^{2}$ test 
Study design All participants were first invited for a screening visit. A general clinical examination was performed and laboratory parameters were screened. If subjects met the inclusion criteria, they were recruited for the following tests: (1) an oral glucose challenge ( $75 \mathrm{~g}$ glucose and/or low-molecular-mass glucose oligomers [O.G.T.; Roche Diagnostics, Mannheim, Germany]), performed with blood being drawn over $240 \mathrm{~min}$ from an indwelling venous cannula; (2) an 'isoglycaemic' intravenous glucose infusion, performed to duplicate the plasma glucose profile determined in the same individual after the oral glucose challenge, and with venous blood drawn over $240 \mathrm{~min}$.

Experimental procedures The tests were performed in the morning after an overnight fast with subjects in a supine position throughout the experiments and the upper body lifted by approximately $30^{\circ}$. One or two forearm veins were punctured with a Teflon cannula (Moskito 123, 18 gauge; Vygon, Aachen, Germany) and kept patent using 0.9\% $\mathrm{NaCl}$ (for blood sampling and for infusions, respectively). Both ear lobes were made hyperaemic using Finalgon (Nonivamid $4 \mathrm{mg} / \mathrm{g}$, Nicoboxil $25 \mathrm{mg} / \mathrm{g}$; Boehringer Ingelheim Pharma, Ingelheim, Germany).

After drawing basal blood specimens at -15 and $0 \mathrm{~min}$, the oral glucose challenges were started by the ingestion of
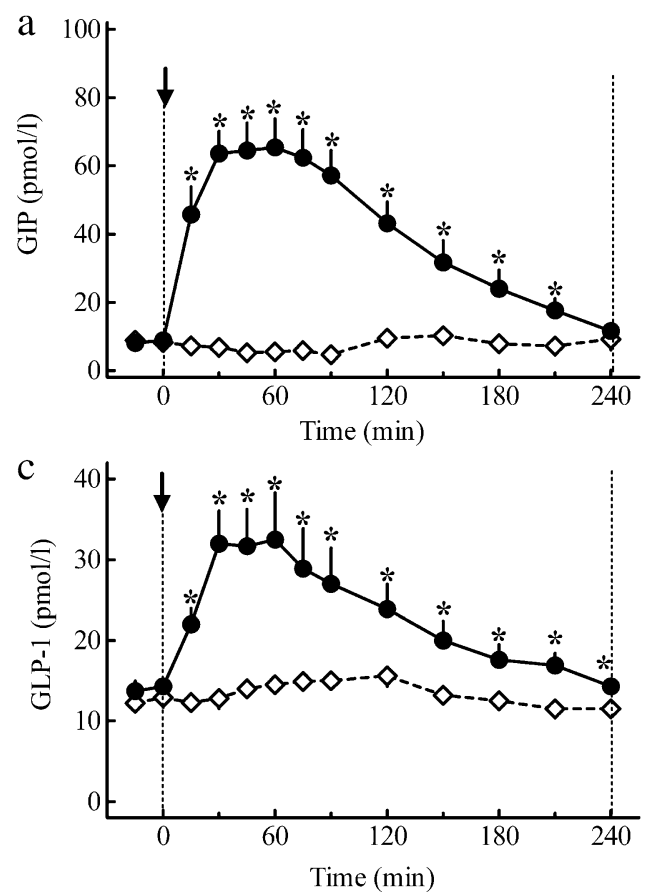

Fig. 1 Plasma concentrations of GIP (a, b) and GLP-1 (c, d) after stimulation with oral glucose ( $75 \mathrm{~g}$; filled circles) or during 'isoglycaemic' intravenous glucose infusion (open diamonds) in ten control subjects $(\mathbf{a}, \mathbf{c})$ and 16 first-degree relatives of patients with type 2 diabetes $(\mathbf{b}, \mathbf{d})$. Beginning of intravenous infusion is marked by dotted vertical line. Arrows indicate the time of oral glucose administration.
$75 \mathrm{~g}$ of oral glucose at $0 \mathrm{~min}$. The 'isoglycaemic' clamp experiments were started by the slow i.v. administration of a small bolus of $40 \%$ glucose at $t=0 \mathrm{~min}$, intended to raise plasma glucose concentrations to levels similar to those measured after oral glucose ingestion. Subsequently, a continuous i.v. infusion of $20 \%$ glucose was started and the infusion rate was adjusted every $5 \mathrm{~min}$ according to the respective plasma glucose measurements. Blood samples were drawn as indicated in Figs. 1 and 2, stored on ice and processed as described [27].

Laboratory determinations Glucose was measured using a glucose oxidase method (Glucose Analyser 2; Beckman Instruments, Munich, Germany). Total GLP-1 concentrations were measured using an RIA (antiserum no. 89390; all antisera raised in the laboratory of J. J. Holst) that is specific for the C-terminal of the GLP-1 molecule and reacts equally with intact GLP-1 and the primary (N-terminally truncated) metabolite as described [27]. Total GIP was measured, as described previously, using the C-terminally directed antiserum R65 [27], which reacts fully with intact GIP and the N-terminally truncated metabolite.

Immunoreactive glucagon was measured by an RIA using antibody no. 4305 in ethanol-extracted plasma, as described [28]. The detection limit was $<1 \mathrm{pmol} / \mathrm{l}$. The intra-assay CV was $6.7 \%$ and inter-assay CV was $16 \%$.
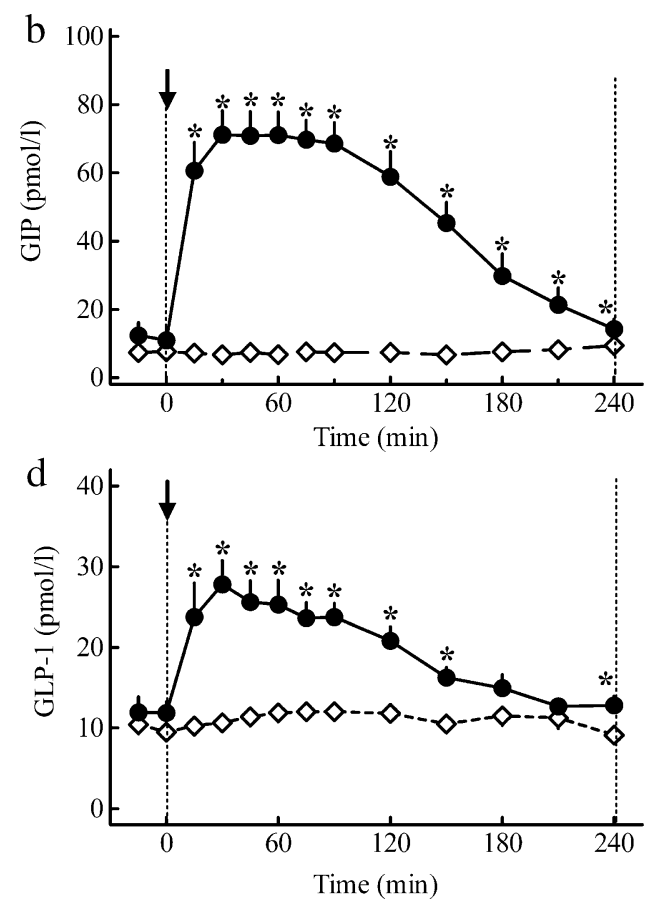

Means \pm SEM. Statistics were carried-out using paired repeated measures ANOVA with the following $p$ values: (1) for differences between the experiments: $p<0.0001$ (a, b, d), $p=0.0031$ (c); (2) for differences over time: $p<0.0001$ (a-d); (3) for differences due to the interaction of experiment and time: $p<0.0001(\mathbf{a}-\mathbf{d}) . *{ }^{*} p<0.05$ for differences at individual time points (one-way ANOVA) 

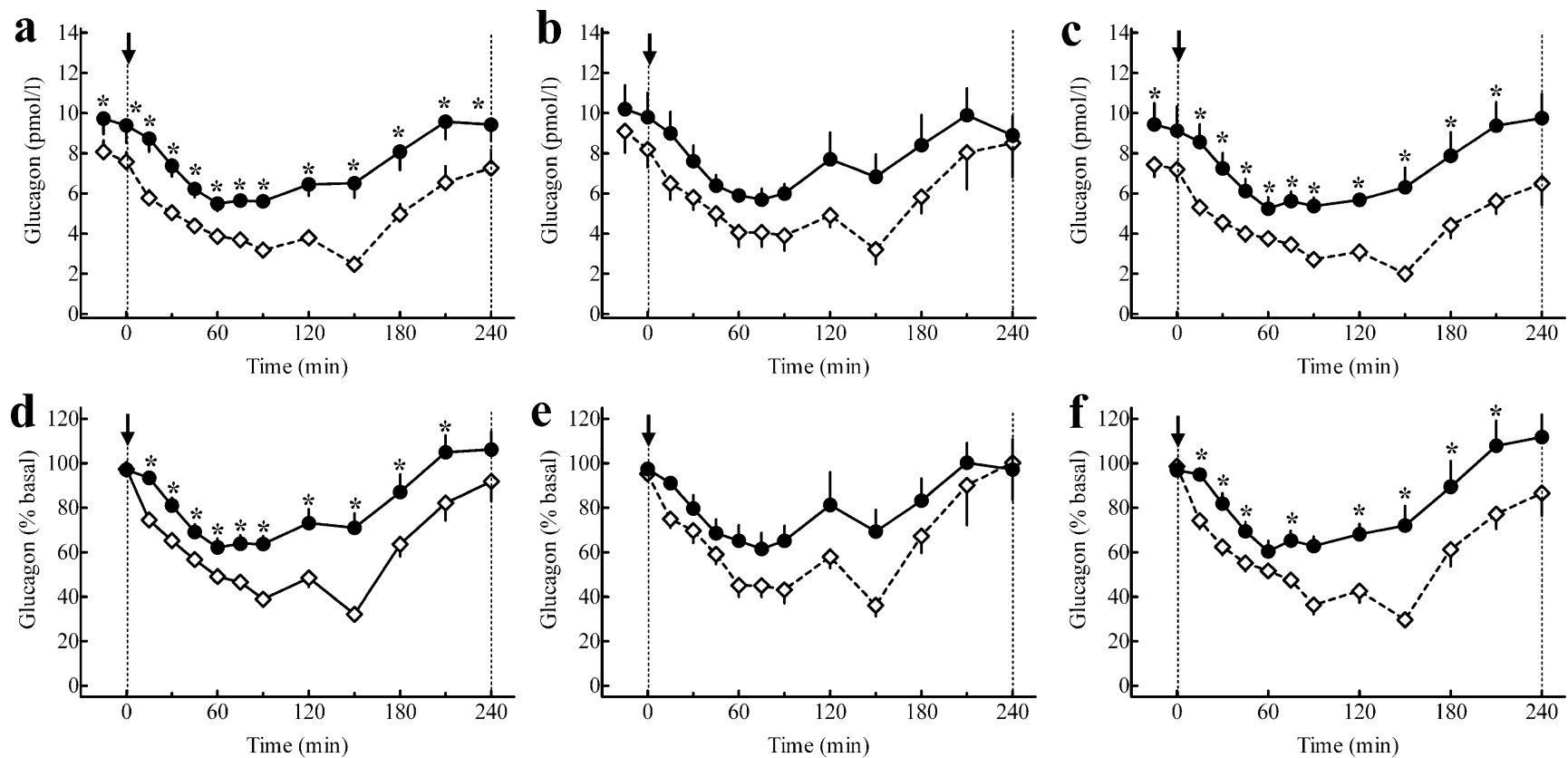

Fig. 2 Glucagon plasma concentrations, expressed as absolute values $(\mathbf{a}-\mathbf{c})$ and as percentage of basal $(\mathbf{d}-\mathbf{f})$ after stimulation with oral glucose (75 g; filled circles) or during 'isoglycaemic' intravenous glucose infusion (open diamonds) in ten control subjects (b, e) and 16 first-degree relatives of patients with type 2 diabetes $(\mathbf{c}, \mathbf{f})$. a, d Results for both groups combined. Beginning of intravenous infusion is marked by dotted vertical line. Arrows indicates the time of oral glucose administration. Means \pm SEM. Statistics were carried-out using paired

Calculations Integrated plasma concentrations of glucagon were calculated using the trapezoidal rule. For the calculation of the maximal suppression of glucagon secretion, the lowest glucagon concentration between 15 and $240 \mathrm{~min}$ was determined and expressed as a percentage of the respective basal glucagon levels (mean value of glucagon concentrations between -15 and $0 \mathrm{~min}$ ).

Statistical analysis Results are reported as mean \pm SEM. All statistical calculations were carried out using repeatedmeasures ANOVA and Statistica, version 5.0 (Statsoft Europe, Hamburg, Germany). Values at single time points were compared by one-way ANOVA followed by Duncan's post hoc test. A two-sided $p$ value $<0.05$ was taken to indicate significant differences.

\section{Results}

Plasma glucose concentrations were similar after oral glucose ingestion and during 'isoglycaemic' intravenous glucose infusion ( $p=0.99$ ). The oral glucose load elicited significant rises in the plasma concentrations of GIP and GLP-1 $(p<0.001)$, whereas incretin levels remained unchanged during intravenous glucose infusion (Fig. 1). There were no differences in the secretion of GIP or GLP-1 between

repeated measures ANOVA with the following $p$ values: (1) for differences between the experiments: $p<0.0001$ (a, c, d), $p=0.0051$ (b), $p=0.07$ (e), $p<0.001$ (f); (2) for differences over time: $p<0.0001$ (a-f); (3) for differences due to the interaction of experiment and time: $p=0.013$ (a), $p=0.59$ (b), $p=0.022$ (c), $\mathrm{p}=0.0011$ (d), $p=0.35$ (e), $p<0.0001$ (f). ${ }^{*} p<0.05$ for differences at individual time points (oneway ANOVA)

first-degree relatives of patients with type 2 diabetes and control subjects ( $p=0.89$ and $p=0.99$, respectively [27]).

Plasma insulin and C-peptide levels measured after oral glucose administration were significantly lower in first-degree relatives than in control subjects $(p<0.001$ and $p=0.011$, respectively, details see [27]). The rise in insulin and Cpeptide concentrations elicited by the oral glucose load was significantly higher (about threefold) than that evoked by the 'isoglycaemic' intravenous glucose infusion $(p<0.0001$, see [27]).

Glucagon levels were significantly suppressed both by oral and by intravenous glucose ( $p<0.0001 ;$ Fig. 2$)$. Interestingly, glucagon concentrations were significantly lower during the 'isoglycaemic' clamp experiments than in the experiments with oral glucose administration, both in first-degree relatives and in controls $(p<0.01$ for the differences between the experiments; Fig. 2a-c). Moreover, when glucagon levels were expressed as a percentage of basal concentrations, the glucose-induced suppression was more pronounced during intravenous than after oral glucose administration $(p<0.0001$ for the interaction of group and time; Fig. 2d).

Integrated glucagon concentrations were $33 \pm 3 \%$ lower during intravenous than after oral glucose $(p<0.001$; Fig. 3). Likewise, the maximal suppression of glucagon levels was significantly more pronounced during intravenous glucose administration than after oral glucose administration $(76 \pm 2 \%$ vs $48 \pm 4 \%$, respectively; $p<0.001$ ). These differ- 
ences in the integrated glucagon concentrations and the maximal suppression of glucagon by glucose administration were present in control subjects and in first-degree relatives of patients with type 2 diabetes (Fig. 3).

Glucagon levels were similar in first-degree relatives of patients with type 2 diabetes and control subjects, both after oral glucose ingestion $(p=0.96)$ and during intravenous glucagon infusion $(p=0.85)$.

There was a significant linear relationship between the basal plasma concentrations of GIP and GLP-1 and the respective plasma glucagon levels $(r=0.73, p<0.0001$ and $r=0.58, p=0.002$, respectively; Fig. 4a,b). Likewise, the differences $(\Delta)$ in the integrated plasma concentrations of GIP and GLP-1 between the experiments with oral and intravenous glucose administration were significantly correlated to the respective differences in glucagon levels $(r=0.60, p=0.001$ for GIP; $r=0.46, p=0.019$ for GLP-1; Fig. $4 \mathrm{c}, \mathrm{d})$.

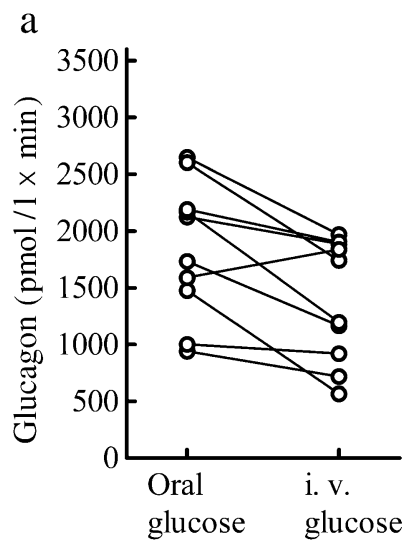

b
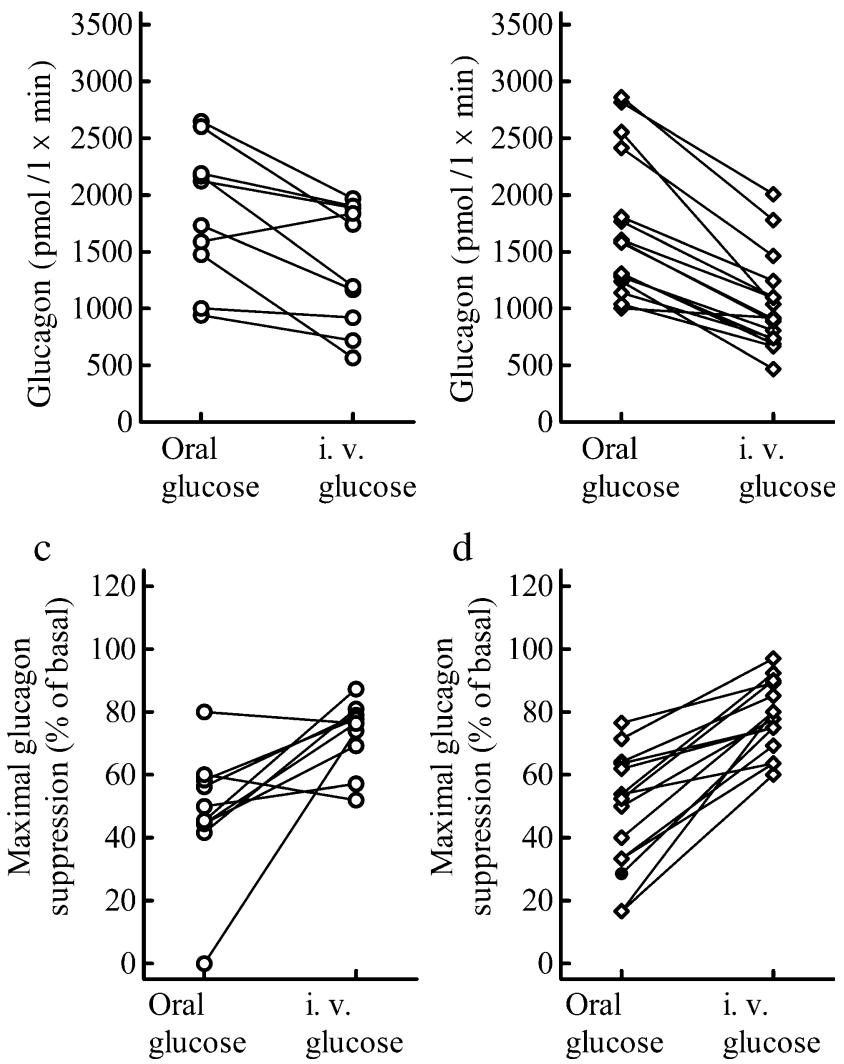

d

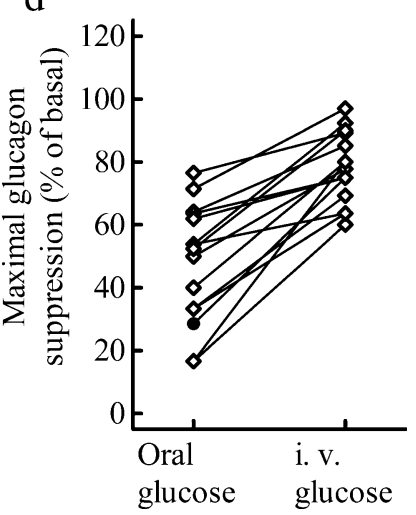

Fig. 3 Integrated glucagon concentrations (0-240 min) and maximal suppression of glucagon levels (0-240 $\mathrm{min})$ after stimulation with oral glucose $(75 \mathrm{~g})$ or during 'isoglycaemic' intravenous glucose infusion in 10 control subjects $(\mathbf{a}, \mathbf{c})$ and 16 first-degree relatives of patients with type 2 diabetes $(\mathbf{b}, \mathbf{d})$. Statistics were carried out using paired one-way ANOVA with the following $p$ values: $p=0.01$ (a); $p<0.0001$ (b); $p=0.001$ (c); $p<0.0001$ (d)

\section{Discussion}

In the present studies we sought to elucidate whether the suppression of glucagon release is different after oral and during 'isoglycaemic' intravenous glucose administration and whether normal glucose-tolerant first-degree relatives of patients with type 2 diabetes already exhibit abnormalities in glucagon secretion. Interestingly, the suppression of glucagon secretion was diminished by about $30 \%$ after oral glucose ingestion compared with the intravenous glucose infusion. These differences in the relative glucagon suppression between oral and intravenous glucose administration were positively associated with the secretion of GIP and GLP-1, consistent with a stimulatory role for the incretin hormones on alpha cell secretion. However, despite detectable alterations in insulin secretion in the first-degree relatives [17, 27], glucagon secretion and its suppression by glucose were unchanged in this group at high risk of contracting type 2 diabetes.

The differences in the extent of glucagon suppression between the experiments with oral and with intravenous glucose are a novel and rather unexpected finding. In fact, given the potent glucagonostatic effects of exogenous GLP1 shown previously in vitro and in vivo $[9,10]$, glucagon levels would, if anything, have been expected to be lower after the oral glucose load. Moreover, in the same experiments the enhancement of insulin secretion was approximately three times greater after oral glucose ingestion than with the 'isoglycaemic' glucose infusion [27], and prior studies have shown that this incretin effect on insulin secretion is specifically accomplished through an amplification of insulin pulse mass [29]. Since the intra-islet pulsatile release of insulin secretion may contribute to the inhibition of alpha cell secretion [30], the augmentation of insulin secretion after oral glucose could be expected to result in a marked inhibition of glucagon release. Therefore, the question arises as to which factors are responsible for the dampening of glucagon suppression after oral glucose. On the basis of the present studies the mechanism underlying this phenomenon cannot be clarified with certainty. However, a possible explanation could be the glucagonotropic effects of GIP and GLP-2 [11-13, 31]. Indeed, GIP has been shown to enhance glucagon release in isolated pancreatic perfusions and in humans in vivo [11, 12]. Consistent with this, the differences in glucagon suppression between oral and i.v. glucose were significantly correlated to the secretion of GIP (Fig. 4). On the other hand, one might argue that the dampening of glucagon secretion was also significantly correlated with GLP-1 secretion (Fig. 4), which is well known to inhibit glucagon release $[9,10]$. However, since the secretion of GLP-1 is tightly linked to that of GLP-2 [32, 33] and GIP [27, 34], it seems possible that this association was indirectly caused 
Fig. 4 Correlation analyses of basal plasma concentrations of glucagon and the respective concentrations of GIP (a) and GLP-1 (b). c, d Correlation analyses of the differences (empty triangle) in the integrated (integral) plasma levels of glucagon and GIP (c) and GLP-1 (d), calculated between experiments with oral and intravenous glucose administration. Closed circles, control subjects; open diamonds, firstdegree relatives of patients with type 2 diabetes. Dashed lines denote the respective upper and lower $95 \%$ CIs. (a) $r=0.73$, $p<0.0001$; (b) $r=0.58$, $p<0.002$; (c) $r=0.60, p<0.001$; (d) $r=0.46, p<0.019$ a
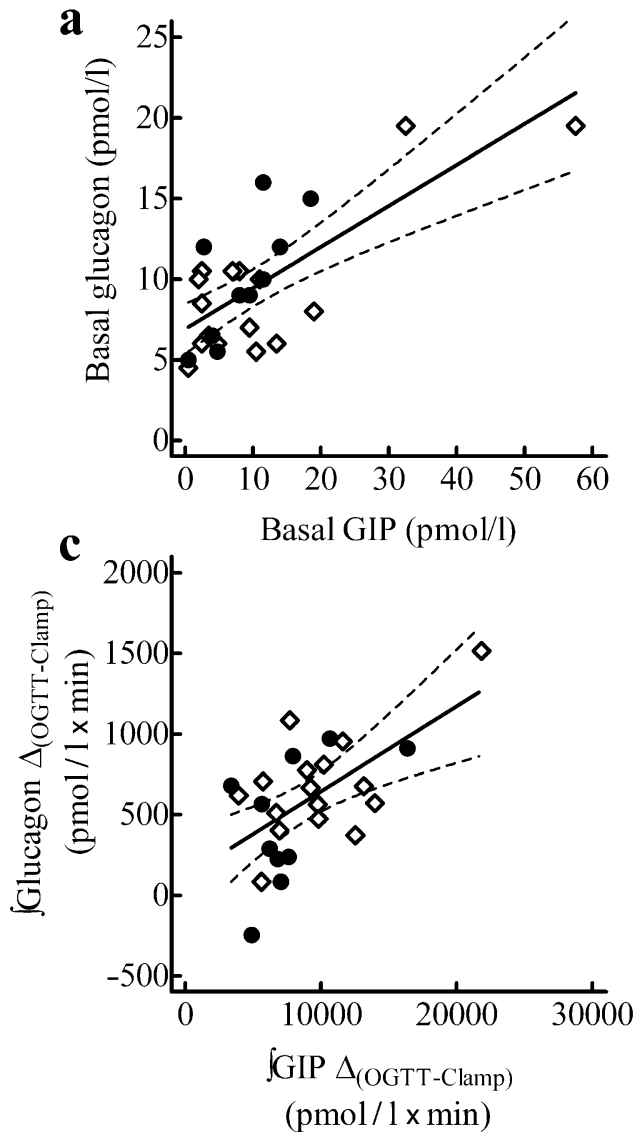

b
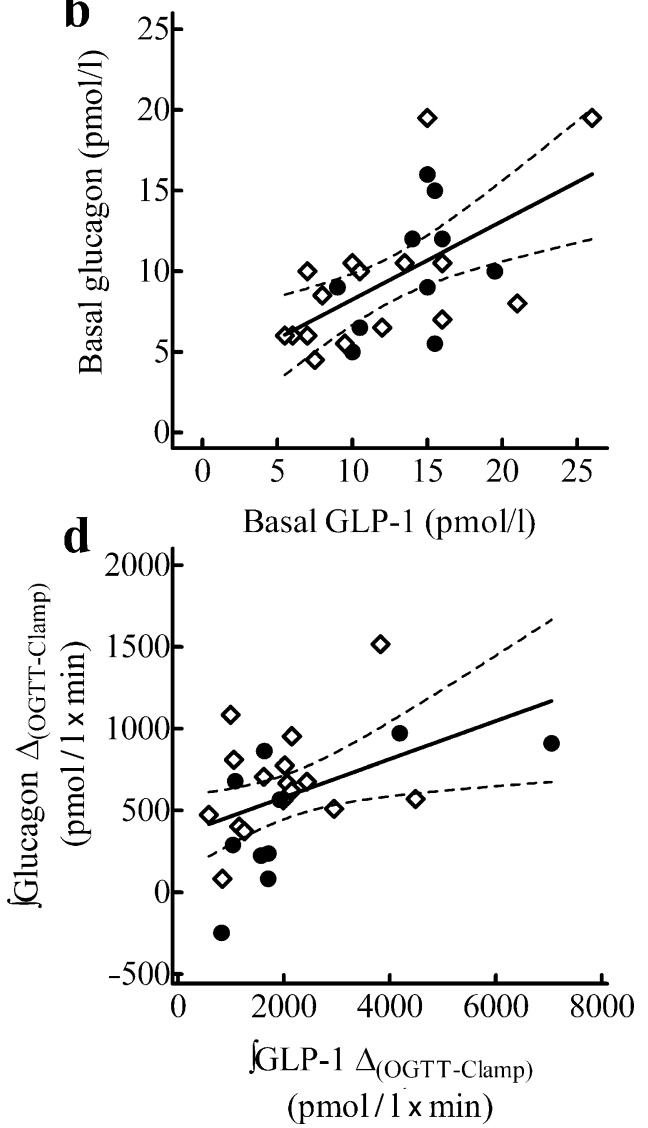

by the concomitant secretion of the glucagonotropic hormones GIP and GLP-2, rather than by the actions of GLP-1 itself. In addition to these humoral factors, other mechanisms, such as a direct neuronal stimulation of glucagon release by oral glucose, e.g. via nerve fibres in the intestinal mucosa or the hepatoportal bed, might be involved in the diminished suppression of glucagon secretion after oral glucose ingestion. Furthermore, a reduction in glucagon extraction after oral glucose cannot be ruled out. In a similar way, for example, the extraction of insulin is markedly reduced after oral, but not during intravenous glucose administration [5, 35]. It should, however, be remembered that the extraction of glucagon (primarily through the kidneys) greatly differs from that of insulin (primarily through the liver) [36, 37].

An alternative explanation for our observation of greater suppression of glucagon secretion after intravenous glucose administration could be a higher initial rise in intra-islet insulin secretion and, subsequently, a more pronounced suppression of alpha cell secretion, given the pivotal role of intra-islet insulin for the regulation of glucagon release [38, 39]. Since intra-islet insulin levels cannot be measured in vivo and systemic insulin measurements were only available 15 min after i.v. glucose administration, the present data do not allow firm conclusions on this potential mechanism.
Another interesting finding is the close association between the fasting concentrations of glucagon and the incretin hormones GIP and GLP-1. This suggests that control of alpha cell secretion by the actions of GIP, GLP-1 and perhaps GLP-2 occurs already at basal conditions. Such reasoning is also consistent with recent studies indicating a role for basal GLP-1 levels in the control of beta cell secretion even under fasting conditions [40, 41].

One potential limitation of 'isoglycaemic' clamp studies is that, by design, the intravenous glucose infusion has to be carried out after the oral glucose challenge, thereby imposing the possibility of an order effect [4]. In the present studies, fasting glucagon levels tended to be higher in the first experiment (oral glucose ingestion) than in the second. However, the dampening of glucagon suppression after glucose ingestion was still apparent when glucagon concentrations were expressed in relation to baseline values. Therefore, the observed differences in the suppression of glucagon secretion between the experiments are unlikely to be due to an order effect.

These studies also demonstrate that the suppression of glucagon secretion by both oral and intravenous glucose is intact in normal glucose-tolerant first-degree relatives of patients with type 2 diabetes, despite defects in beta cell function being already detectable in such subjects [17, 27]. 
This is in contrast to previous studies in subjects with IGT, in which the suppression of glucagon release after meal ingestion was impaired, thereby leading to a diminished reduction of hepatic glucose output [25]. However, in these subjects with IGT, fasting glucose concentrations were about $1.1 \mathrm{mmol} / \mathrm{l}(20 \mathrm{mg} / \mathrm{dl})$ higher than in the present group of normal glucose-tolerant first-degree relatives of patients with type 2 diabetes. Moreover, the degree of beta cell dysfunction in subjects with IGT appears to be of greater magnitude than that in the present cohort of firstdegree relatives [42], and recent autopsy studies in subjects with IFG have revealed that beta cell mass is already about $50 \%$ deficient in such individuals [43]. Therefore, the present data showing a preserved suppression of glucagon secretion in first-degree relatives of patients with type 2 diabetes do not support the hypothesis that hyperglucagonaemia represents a primary defect in type 2 diabetes. Rather, the lack of glucagon suppression after meal ingestion observed in some patients with type 2 diabetes may develop later in the pathogenesis of the disease, possibly as a consequence of other metabolic defects such as impaired insulin secretion.

In conclusion, the present studies have shown that the suppression of glucagon secretion by hyperglycaemia is diminished after oral glucose administration. The differences in glucagon suppression between oral and intravenous glucose administration are closely related to the secretion of incretin hormones, consistent with a stimulatory role for GIP and perhaps GLP-2. Furthermore, the suppression of glucagon release after oral and intravenous glucose is preserved in normal glucose-tolerant first-degree relatives of patients with type 2 diabetes. This indicates that in this group at high risk of type 2 diabetes, abnormalities in glucagon secretion do not precede the development of hyperglycaemia.

Acknowledgements We are indebted to K. Huecking and B. Gabrys for help with the clamp procedures and to B. Gallwitz for critical discussion and helpful suggestions. The excellent technical assistance of $\mathrm{K}$. Mros and L. Bagger is greatly acknowledged. This study was supported by grants from the Deutsche Diabetes Gesellschaft and the Deutsche Forschungsgemeinschaft (grants Na 203/6-1 and Me 2096/3-1).

Duality of interest The authors have no dualities of interest to report.

\section{References}

1. Gerich JE (2000) Physiology of glucose homeostasis. Diabetes Obes Metab 2:345-350

2. Meier JJ, Butler PC (2005) Insulin secretion. In: Jameson JL (ed) Endocrinology, 5th edn. Elsevier, Philadelphia, pp 961-973
3. Perley MJ, Kipnis DM (1967) Plasma insulin responses to oral and intravenous glucose: studies in normal and diabetic subjects. J Clin Invest 46:1954-1962

4. Nauck MA, Homberger E, Siegel EG et al (1986) Incretin effects of increasing glucose loads in man calculated from venous insulin and C-peptide responses. J Clin Endocrinol Metab 63:492-498

5. Shuster LT, Go VLW, Rizza RA, O'Brien PC, Service FJ (1988) Incretin effect due to increased secretion and decreased clearance of insulin in normal humans. Diabetes 37:200-203

6. Creutzfeldt W (1979) The incretin concept today. Diabetologia 16:75-85

7. Nauck MA, Bartels E, Ørskov C, Ebert R, Creutzfeldt W (1993) Additive insulinotropic effects of exogenous synthetic human gastric inhibitory polypeptide and glucagon-like peptide-1-(7-36) amide infused at near-physiological insulinotropic hormone and glucose concentrations. J Clin Endocrinol Metab 76:912-917

8. Vilsbøll T, Krarup T, Madsbad S, Holst JJ (2003) Both GLP-1 and GIP are insulinotropic at basal and postprandial glucose levels and contribute nearly equally to the incretin effect of a meal in healthy subjects. Regul Pept 114:115-121

9. Ørskov C, Holst JJ, Nielsen OV (1988) Effect of truncated glucagon-like peptide-1 [proglucagon-(78-107) amide] on endocrine secretion from pig pancreas, antrum, and nonantral stomach. Endocrinology 123:2009-2013

10. Nauck MA, Kleine N, Ørskov C, Holst JJ, Willms B, Creutzfeldt W (1993) Normalization of fasting hyperglycaemia by exogenous glucagon-like peptide 1 (7-36 amide) in type 2 (non-insulindependent) diabetic patients. Diabetologia 36:741-744

11. Pederson RA, Brown JC (1978) Interaction of gastric inhibitory polypeptide, glucose, and arginine on insulin and glucagon secreton from the perfused rat pancreas. Endocrinology 103:610-615

12. Meier JJ, Gallwitz B, Siepmann N et al (2003) Gastric inhibitory polypeptide (GIP) dose-dependently stimulates glucagon secretion in healthy human subjects at euglycaemia. Diabetologia 46:798-801

13. Meier JJ, Nauck MA, Pott A et al (2006) Glucagon-like peptide 2 stimulates glucagon secretion, enhances lipid absorption, and inhibits gastric acid secretion in humans. Gastroenterology 130:44-54

14. Nauck M, Stöckmann F, Ebert R, Creutzfeldt W (1986) Reduced incretin effect in type 2 (non-insulin-dependent) diabetes. Diabetologia 29:46-54

15. Krarup T, Saurbrey N, Moody AJ, Kühl C, Madsbad S (1988) Effect of porcine gastric inhibitory polypeptide on $\beta$-cell function in type 1 and type II diabetes mellitus. Metabolism 36:677-682

16. Nauck MA, Heimesaat MM, Ørskov C, Holst JJ, Ebert R, Creutzfeldt W (1993) Preserved incretin activity of glucagon-like peptide 1 [7-36 amide] but not of synthetic human gastric inhibitory polypeptide in patients with type- 2 diabetes mellitus. J Clin Invest 91:301-307

17. Meier JJ, Hücking K, Holst JJ, Deacon C, Schmiegel W, Nauck MA (2001) Reduced insulinotropic effect of gastric inhibitory polypeptide in first-degree relatives of patients with type 2 diabetes. Diabetes 50:2497-2504

18. Toft-Nielsen MB, Damholt MB, Madsbad S et al (2001) Determinants of impaired secretion of glucagon-like peptide-1 in type 2 diabetic patients. J Clin Endocrinol Metab 86:3717-3723

19. Vilsbøll T, Krarup T, Deacon CF, Madsbad S, Holst JJ (2001) Reduced postprandial concentrations of intact biologically active glucagon-like peptide 1 in type 2 diabetic patients. Diabetes 50:609-613

20. Nauck MA, Baller B, Meier JJ (2004) Gastric inhibitory polypeptide and glucagon-like peptide-1 in the pathogenesis of type 2 diabetes. Diabetes 53(Suppl 3):S190-S196

21. Unger RH, Aguilar-Parada E, Muller WA, Eisentraut AM (1970) Studies of pancreatic alpha cell function in normal and diabetic subjects. J Clin Invest 49:837-848 
22. Unger RH, Orci L (1977) Role of glucagon in diabetes. Arch Intern Med 137:482-491

23. Gerich JE (1989) Abnormal glucagon secretion in type 2 (noninsulin-dependent) diabetes mellitus: Causes and consequences. In: Creutzfeldt W, Lefèbvre P (eds) Diabetes mellitus: Pathophysiology and therapy. Springer, Berlin Heidelberg New York, pp 127-133

24. Larsson H, Ahren B (2000) Glucose intolerance is predicted by low insulin secretion and high glucagon secretion: outcome of a prospective study in postmenopausal Caucasian women. Diabetologia 43:194-202

25. Mitrakou A, Kelley D, Mokan M et al (1992) Role of reduced suppression of glucose production and diminished early insulin release in impaired glucose tolerance. N Engl J Med 326:22-29

26. Gerich JE (1998) The genetic basis of type 2 diabetes mellitus: impaired insulin secretion versus impaired insulin sensitivity. Endocrine Rev 19:491-503

27. Nauck MA, El-Ouaghlidi A, Gabrys B et al (2004) Secretion of incretin hormones (GIP and GLP-1) and incretin effect after oral glucose in first-degree relatives of patients with type 2 diabetes. Regul Pept 122:209-217

28. Holst JJ (1982) Evidence that peak II GLI or enteroglucagon is identical to the C-terminal sequence (residues 33-69) of glicentin. Biochem J 207:381-388

29. Porksen N, Munn S, Steers J, Veldhuis JD, Butler PC (1996) Effects of glucose ingestion versus infusion on pulsatile insulin secretion. The incretin effect is achieved by amplification of insulin secretory burst mass. Diabetes 45:1317-1323

30. Meier JJ, Kjems LL, Veldhuis JD, Lefebvre P, Butler PC (2006) Postprandial suppression of glucagon secretion depends on intact pulsatile insulin secretion: further evidence for the intraislet insulin hypothesis. Diabetes 55:1051-1056

31. Sørensen LB, Flint A, Raben A, Hartmann B, Holst JJ, Astrup A (2003) No effect of physiological concentrations of glucagon-like peptide- 2 on appetite and energy intake in normal weight subjects. Int J Obes Relat Metab Disord 27:450-456

32. Ørskov C, Knuhtsen S, Baldissera FG, Poulsen SS, Nielsen OV, Holst JJ (1986) Glucagon-like peptides GLP-1 and GLP-2, predicted products of the glucagon gene, are secreted separately from pig small intestine but not pancreas. Endocrinology 119:1467-1475
33. Bell GI, Santerre RF, Mullenbach GT (1983) Hamster preproglucagon gene contains the sequence of glucagon and two related peptides. Nature 302:716-718

34. Mortensen K, Petersen LL, Holst JJ, Ørskov C (2003) GLP-1 and GIP are colocalized in a subset of endocrine cells in the small intestine. Regul Pept 114:189-196

35. Meier JJ, Gallwitz B, Siepmann N et al (2003) The reduction in hepatic insulin clearance after oral glucose is not mediated by gastric inhibitory polypeptide (GIP). Regul Pept 113:95-100

36. Holst JJ (1991) Degradation of pancreatic peptides: Glucagon. In: Henriksen JH (ed) Degradation of bioactive substances, physiology and pathophysiology. CRC, Boca Raton pp 167-180

37. Deacon CF, Kelstrup M, Trebbien R, Klarskov L, Olesen M, Holst JJ (2003) Differential regional metabolism of glucagon in anesthetized pigs. Am J Physiol Endocrinol Metab 285:E552-E560

38. Raju B, Cryer PE (2005) Loss of the decrement in intraislet insulin plausibly explains loss of the glucagon response to hypoglycemia in insulin-deficient diabetes: documentation of the intraislet insulin hypothesis in humans. Diabetes 54:757-7764

39. Hope KM, Tran PO, Zhou H, Oseid E, Leroy E, Robertson RP (2004) Regulation of alpha-cell function by the beta-cell in isolated human and rat islets deprived of glucose: the "switchoff' hypothesis. Diabetes 53:1488-1495

40. Masur K, Tibaduiza EC, Chen C, Ligon B, Beinborn M (2005) Basal receptor activation by locally produced glucagon-like peptide-1 contributes to maintaining beta-cell function. Mol Endocrinol 19:1373-1382

41. Serre V, Dolci W, Schaerer E et al (1998) Exendin-(9-39) is an inverse agonist of the murine glucagon-like peptide-1 receptor: implications for basal intracellular cyclic adenosine 3',5'-monophosphate levels and beta-cell glucose competence. Endocrinology 139:4448-4454

42. Fritsche A, Stefan N, Hardt E, Häring H, Stumvoll M (2000) Characterisation of beta-cell dysfunction of impaired glucose tolerance: evidence for impairment of incretin-induced insulin secretion. Diabetologia 43:852-858

43. Butler AE, Janson J, Bonner-Weir S, Ritzel R, Rizza RA, Butler PC (2003) Beta-cell deficit and increased beta-cell apoptosis in humans with type 2 diabetes. Diabetes 52:102-110 